OPEN ACCESS

Edited by:

Alberto A. Rasia-Filho,

Federal University of Health Sciences

of Porto Alegre, Brazil

Reviewed by:

Tom Reese

National Institute of Neurological Disorders and Stroke-NINDS (NIH), United States

Joachim H. R. Lübke,

Forschungszentrum Jülich, Germany

*Correspondence:

Ronald S. Petralia petralia@nidcd.nih.gov

Received: 19 December 2017 Accepted: 19 March 2018 Published: 05 April 2018

Citation:

Petralia RS, Wang Y-X, Mattson MP and Yao PJ (2018) Invaginating Structures in Mammalian Synapses. Front. Synaptic Neurosci. 10:4. doi: 10.3389/fnsyn.2018.00004

\section{Invaginating Structures in Mammalian Synapses}

\author{
Ronald S. Petralia ${ }^{1 *}$, Ya-Xian Wang ${ }^{1}$, Mark P. Mattson ${ }^{2}$ and Pamela J. Yao ${ }^{2}$ \\ ${ }^{1}$ Advanced Imaging Core, NIDCD/NIH, Bethesda, MD, United States, ${ }^{2}$ Laboratory of Neurosciences, National Institute on \\ Aging, Intramural Research Program, Baltimore, MD, United States
}

Invaginating structures at chemical synapses in the mammalian nervous system exist in presynaptic axon terminals, postsynaptic spines or dendrites, and glial processes. These invaginating structures can be divided into three categories. The first category includes slender protrusions invaginating into axonal terminals, postsynaptic spines, or glial processes. Best known examples of this category are spinules extending from postsynaptic spines into presynaptic terminals in forebrain synapses. Another example of this category are protrusions from inhibitory presynaptic terminals invaginating into postsynaptic neuronal somas. Regardless of the direction and location, the invaginating structures of the first category do not have synaptic active zones within the invagination. The second category includes postsynaptic spines invaginating into presynaptic terminals, whereas the third category includes presynaptic terminals invaginating into postsynaptic spines or dendrites. Unlike the first category, the second and third categories have active zones within the invagination. An example of the second category are mossy terminal synapses of the hippocampal CA3 region, in which enlarged spine-like structures invaginate partly or entirely into mossy terminals. An example of the third category is the neuromuscular junction (NMJ) where substantial invaginations of the presynaptic terminals invaginate into the muscle fibers. In the retina, rod and cone synapses have invaginating processes from horizontal and bipolar cells. Because horizontal cells act both as post and presynaptic structures, their invaginating processes represent both the second and third category. These invaginating structures likely play broad yet specialized roles in modulating neuronal cell signaling.

Keywords: CA3, horizontal cell, retina, neuromuscular, ephaptic, spinule, cannabinoid, indented

\section{INTRODUCTION}

The classic image of a neuronal synapse with a bulbous presynaptic terminal separated from a postsynaptic dendrite shaft or spine (Figure 1A; Shepherd, 2004) is often, in reality, complicated by various invaginating structures. Even sponges, which seem to lack definitive neurons and chemical synapses, can have neuron-like cells with elongate processes making invaginating contacts with other cell processes; perhaps these invaginating contacts represent rudimentary chemical synapses. Some cubozoan jellyfish possess highly developed eyes with photoreceptor synapses that have complex invaginating postsynaptic spines. In fact, almost all major groups of animals, invertebrate and vertebrate, have a variety of invaginating structures at many of their synapses. 


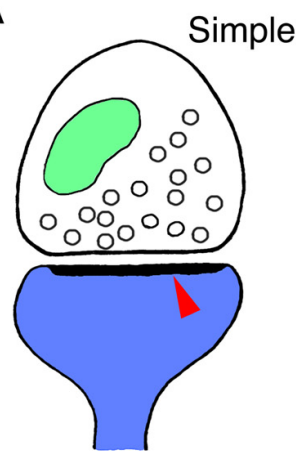

C
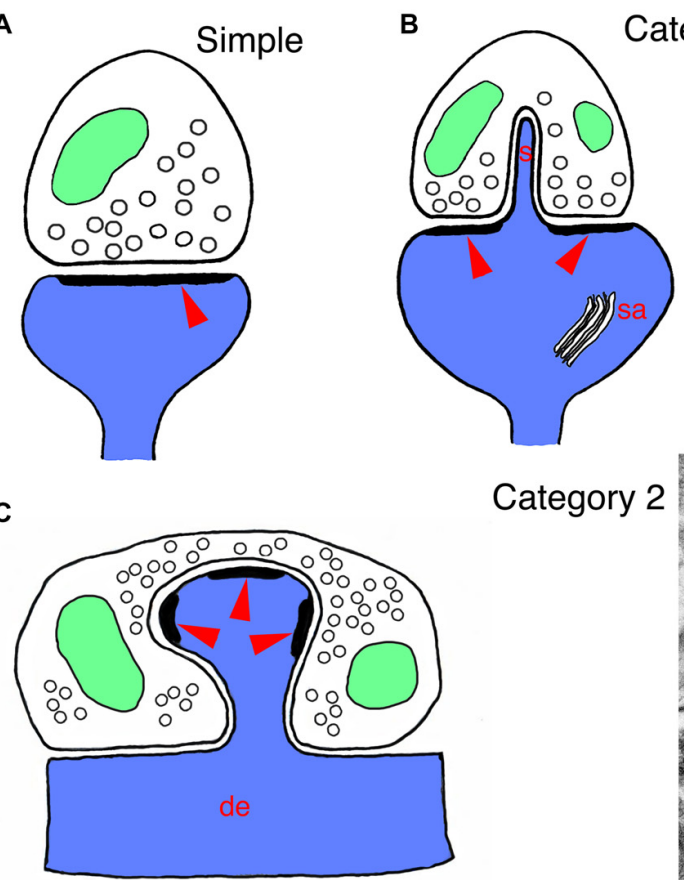

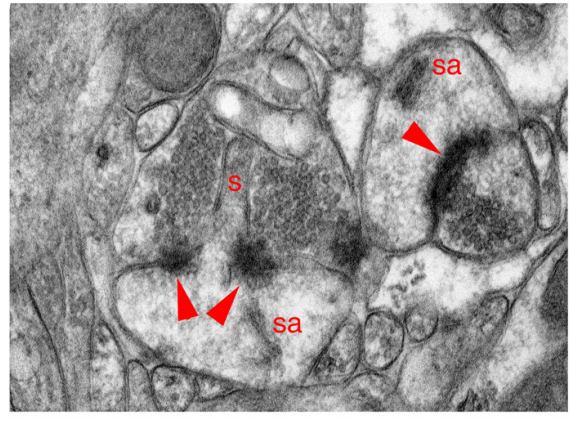

Category 2

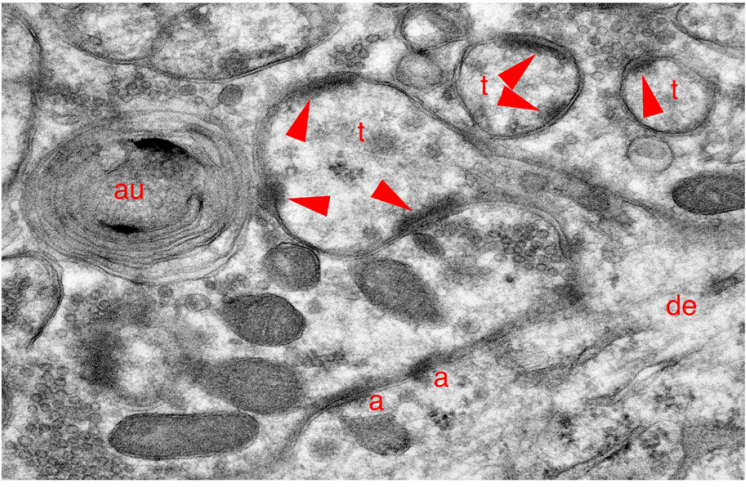

Category 3
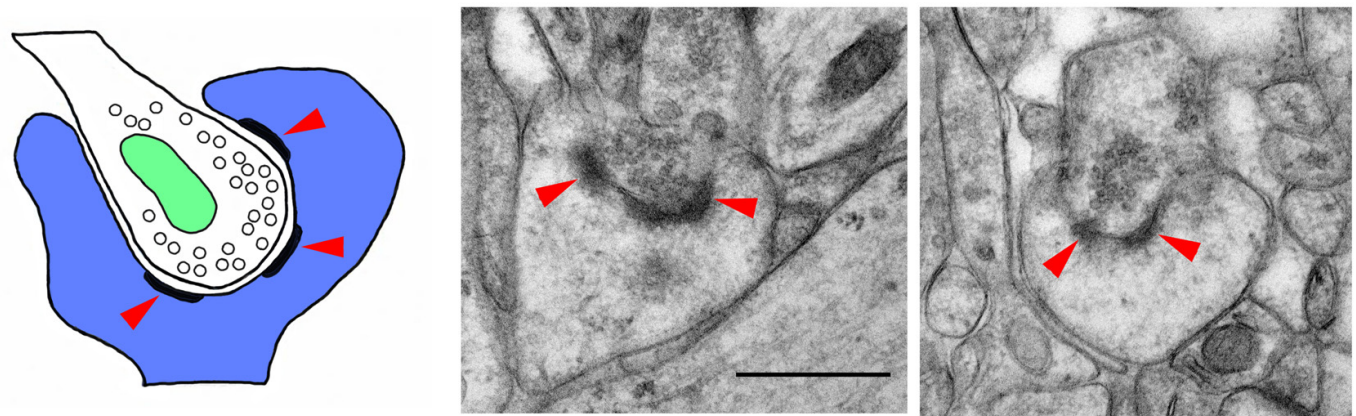

FIGURE 1 | Drawings and EM micrographs illustrating basic examples of the three categories of invaginating structures in mammalian synapses. In all drawings, postsynaptic structures are blue, presynaptic structures are white, mitochondria are green and red arrowheads indicate the postsynaptic densities of synapses. (A) A typical or regular postsynaptic spine forming a synapse with a presynaptic terminal. Arrowhead indicates the postsynaptic density (PSD) that is opposite the active zone, where synaptic vesicles fuse with the presynaptic membrane. (B) A drawing of a category $\mathbf{1}$ invaginating structure shows a large mushroom spine with a spinule (s) that invaginates into the presynaptic terminal; mushroom spines often have a spine apparatus (sa). These large spines with spinules are associated with plasticity and spatial learning. The EM micrograph shows a spinule from a mushroom spine, invaginating into the presynaptic terminal (molecular layer of the dentate gyrus of adult rat). (C) A drawing of a category 2 invaginating structure shows a postsynaptic spine protruding from a dendrite and invaginating into a presynaptic terminal. The EM micrograph was taken from the CA3 region of an adult hippocampus. It shows a Mossy fiber terminal (MFT) forming synapses on the spine-like thorny excrescences $(t)$ extending from the apical dendrites of pyramidal cell neurons. The MFTs also form adherens junctions (a; a.k.a. attachment plaques) with the apical dendrite (de). Note also that a cluster of synaptic vesicles has been enwrapped by phagophores to form an autophagosome (au; Petralia et al., 2011; Vijayan and Verstreken, 2017). (D) A drawing of a category $\mathbf{3}$ invaginating structure shows a presynaptic terminal invaginating into a postsynaptic process. The EM micrographs were taken from an adult rat dentate gyrus, and show cup spines with partially invaginating presynaptic terminals. The small terminal on the left is almost fully below the edge of the cup, while the terminal on the right is only partially invaginated; in some examples of cup spines described in the literature, the presynaptic terminal can be fully invaginating into the spine (see text for details). Note that tissue for EM in Figures $\mathbf{1}, \mathbf{2}$ was prepared using freeze substitution, and sections were stained with uranyl acetate and lead citrate (Petralia and Wenthold, 1999; Petralia et al., 2010). Scale bar in the two figures is 500 nm. Animal procedures were performed in accordance with guidelines approved by the institute Animal Care and Use Committee and $\mathrm{NIH}$.

These invaginating structures can originate from the postsynaptic process, the presynaptic terminal, or glial processes. Many types of invaginating structures do not contain or contact active zones (for example, Figure 1B). These active zone-free invaginating structures have been given various names including spinules, varicosities, and protrusions. In contrast, active zone-associated invaginating structures can be derived from postsynaptic processes that include postsynaptic spines and spine-like structures, or from part or all of the presynaptic terminal. We have previously described three categories of 
invaginating structures in all animals (Petralia et al., 2015, 2016, 2017). In this short review, we focus on the three categories in mammals, and update the literature. We also discuss how all these invaginations can be essential for precise signaling events among neurons, and contribute to synaptic signaling.

\section{EXAMPLES OF INVAGINATING STRUCTURES AT MAMMALIAN SYNAPSES}

\section{Category 1. Invaginating Spinules and Related Structures}

These invaginating protrusions can be derived from the postsynaptic, presynaptic or glial components of synapses. Although active zones often lie adjacent to the invaginating structures, they do not have any active zone within the invagination (see Figure 1B).

\section{Postsynaptic}

In mammals, postsynaptic spinules have been described best in rat hippocampus, but spinules are found in other parts of the brain such as cerebral cortex and cerebellum (Figures 1, 2; Blanque et al., 2015; Petralia et al., 2015; Familtsev et al., 2016; Rodriguez-Moreno et al., 2017). In the adult rat CA1 stratum radiatum, Westrum and Blackstad (1962) found that spinules are 25-100 nm wide and 75-150 nm long, but Spacek and Harris (2004) found greater variation in size (diameters from $<8 \mathrm{~nm}$ to $150 \mathrm{~nm}$ ), with some dendritic spine spinules longer than $0.75 \mu \mathrm{m}$; and Tao-Cheng et al. (2009) found postsynaptic spinules as long as $0.5 \mu \mathrm{m}$ in hippocampal slice cultures. Postsynaptic spinules include those that invaginate into presynaptic terminals, as well as some that invaginate into adjacent axonal or glial processes (Spacek and Harris, 2004). Often the tip of the spinule is surrounded by a coated pit in the opposing cell membrane (hippocampus (Westrum and Blackstad, 1962; Spacek and Harris, 2004; Yao et al., 2005; Tao-Cheng et al., 2009); cerebellum (Eckenhoff and Pysh, 1979)). Spacek and Harris (2004) suggest that: “...spinules provide a general mechanism for signaling and remodeling throughout the brain". Postsynaptic spinules are involved in synaptic plasticity that occurs during all stages of life, from early postnatal development to old age; one of the best studied examples of synaptic plasticity that involves spinules occurs in large, mushroom-shaped spines of the hippocampus (reviewed in Geinisman et al., 1994; Petralia et al., 2014). Typically, during plasticity such as that initiated by long-term potentiation (LTP), the mushroom spine grows in size (and adds postsynaptic receptor molecules) and a perforation forms in the center of the postsynaptic density (PSD). At the perforation, the postsynaptic membrane may begin to invaginate into the presynaptic terminal as a spinule (Figure 1B); eventually, the PSD may separate into pieces (segmentation) as the spine continues to grow. These spines may go through cycles of enlargement and shrinkage associated with activity and aging. Also, the associated spinules undergo rapid turnover during sustained synaptic activity; this may be a mechanism of membrane retrieval by the presynaptic terminal to compensate for excessive growth of spine membrane induced by activity (Tao-Cheng et al., 2009).

\section{Presynaptic}

In adult rat hippocampus stratum radiatum, as described above, most spinules originate from postsynaptic structures, but Spacek and Harris (2004) found that about 12\% grow from axons and invaginate into other axons or glia. In several regions of the limbic system, such as the globus pallidus, axon terminals can interlock with each other along their lateral surfaces via large processes called pseudopodial indentations (Boyne and Tarrant, 1982). These might function as "variable diffusion traps" that control ions in the extracellular spaces between adjacent terminals, thus probably influencing their membrane potentials. In the dentate gyrus, entorhinal cortex and basolateral amygdala, some inhibitory GABAergic terminals extend short invaginating projections into the postsynaptic neuron; the presynaptic membrane contains cannabinoid receptors, and the invaginating projection opposes a part of the postsynaptic membrane that is rich in an enzyme, DGL $\alpha$, that synthesizes an endogenous cannabinoid (Figure 2A; Yoshida et al., 2011; Omiya et al., 2015). This structure mediates a retrograde cannabinoid signal producing specific tonic inhibition of synaptic activity. Other interesting examples of presynaptic invaginating structures include thin spinules in early postnatal rodents extending from auditory hair cells and from cerebellar parallel fibers, into postsynaptic afferent processes or Purkinje cell dendrites, respectively (see Petralia et al., 2015). Also, Brusco et al. (2014) shows examples of both presynaptic and postsynaptic spinules in the amygdala.

\section{Glial}

Glial-derived invaginating projections are common in invertebrates and some lower vertebrates, including at synapses and associated with other parts of neurons (Petralia et al., 2015), but relatively few have been described in mammals. In the cat, Schwann cell processes from the surrounding myelin sheath can extend small invaginating processes into spiral ganglion neurons (Adamo and Daigneault, 1973). Various kinds of glial processes commonly invaginate into axons of mammals (Spencer and Thomas, 1974). One kind involves invaginating "tongues" or "protrusions" originating from surrounding Schwann or oligodendrocyte cytoplasm; these processes appear to ensheath and remove groups of abnormal axonal organelles, and are more common in diseased axons (Spencer and Thomas, 1974). Small spinules also can invaginate into axons from surrounding glia; these typically end in coated pits in axons; Novotny (1984) suggests that glia utilize these structures to transfer substances essential for axonal function.

\section{Category 2. Invaginating Postsynaptic Spines}

These postsynaptic spines protrude directly into the presynaptic terminal and contain active zones within the invagination (Figure 1C).

The best examples in mammals, in the hippocampal CA3 region and retina, are described separately. Other 

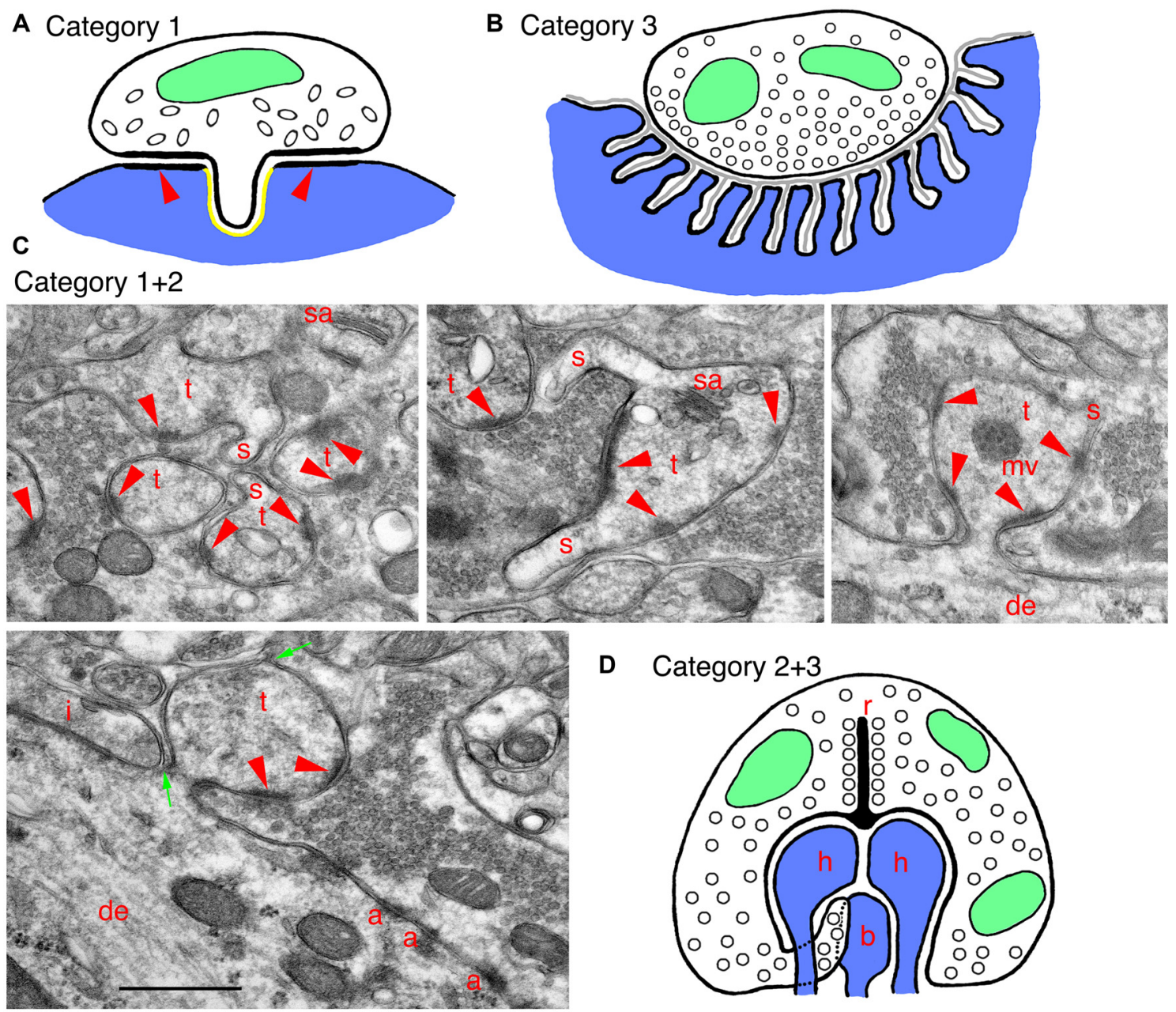

FIGURE 2 | Examples of specialized invaginating structures. (A) A drawing of an unusual example of a category $\mathbf{1}$ invaginating structure: a presynaptic terminal invaginates into the postsynaptic soma. The synapse has characteristics of inhibitory terminals with a less prominent PSD (arrowheads) and oval-shaped synaptic vesicles. The GABA receptors are on the postsynaptic membrane, lining the PSD (arrowheads) and ringing the invagination, and there are endocannabinoid synthetic enzymes on the postsynaptic side of the invagination (shown in yellow). Endocannabinoid release activates cannabinoid receptors in the presynaptic membrane, and these then mediate retrograde suppression of neurotransmitter release from the terminal. (B) A drawing of a specialized example of a category $\mathbf{3}$ invaginating structure: a generalized mammalian neuromuscular junction (NMJ). In this example, the presynaptic terminal is only partly invaginated (indented) into the muscle fiber. The indention is lined with deep subjunctional folds in the postsynaptic membrane. A thin basal lamina (gray) extends within the synaptic cleft and into the folds. (C) EM micrographs show examples of invaginating structures combining categories $\mathbf{1}$ and $\mathbf{2}$. These are from the CA3 MFT region, as described in Figure 1C Thorny excrescences (category 2) also commonly invaginate spinules (s; category 1) into the MFTs, especially apparent in the upper three micrographs. Note in the left, lower micrograph how thin portions of the MFT shown between the two green arrows surround part of the invaginated thorny excrescence. A tiny spinule is barely visible near the top green arrow. Note also how this MFT isolates the thorny excrescence surface from possible spillover from an adjacent inhibitory terminal (i); the latter is identified by the elongate symmetrical density as well as by some obscure pleomorphic synaptic vesicles (compare to the more distinctive and rounder excitatory synaptic vesicles in the MFTs). Common organelles in the thorny excrescences include the spine apparatus (sa) and multivesicular body (mv).

(D) A drawing of a specialized invaginating structure combining categories $\mathbf{2}$ and $\mathbf{3}$. A photoreceptor terminal-synaptic ribbon (r) contacts a deep invagination containing postsynaptic processes (category 2) from horizontal (h) and bipolar (b) neurons, as well as projections from the terminal. Rod terminals in mammals usually have a single invaginated ribbon/active zone with two horizontal and two bipolar cell processes, as well as "fingers" of rod cytoplasm, while cone terminals have multiple invaginated ribbon/active zones, each with two horizontal and 1-2 bipolar cell processes (Rao-Mirotznik et al., 1995; Sterling and Demb, 2004; Petralia et al., 2017). The horizontal cell processes also may act as invaginating presynaptic terminals (category 3) since they send a retrograde signal to the photoreceptor terminal, mediating a feedback mechanism.

interesting examples of invaginating spines include: spines invaginating into early-postnatal developing auditory hair cells of the mouse and into giant terminals called endbulbs of Held in the anteroventral cochlear nucleus of the early postnatal cat, some invaginating filopodia-like spines in the red nucleus, and those forming some crest synapses (for details, see Petralia et al., 2016). Note that various structures called filopodia are common in the nervous system; they look like spinules, only are larger-usually $>100 \mathrm{~nm}$ wide and $>1 \mu \mathrm{m}$ long, and usually are not invaginating. Like spines, filopodia contain 
actin filaments; in contrast, the content of spinules is generally diffuse and poorly defined, and it may be difficult to distinguish wide spinules from thin filopodia. Some filopodia may mediate synaptogenesis of spine synapses and be important components of synaptic plasticity and learning (Fiala et al., 1998; Ozcan, 2017). Crest synapses are particularly unusual, and consist of a flattened, disk-shaped spine with synaptic active zones on the two sides, either invaginating into a single terminal or having two terminals-one per side; they are found scattered throughout the central nervous system (Akert et al., 1967; Petralia et al., 2016). In addition, afferents to taste bud cells often form spine-like indented or invaginated synapses in many mammals (Royer and Kinnamon, 1988, 1991; Witt and Reutter, 1996); the more deeply invaginating ones are described as finger-like projections or processes (Royer and Kinnamon, 1988, 1991).

\section{Category 3. Invaginating Presynaptic Terminals}

These presynaptic terminals protrude directly into the postsynaptic structure (spine or dendrite) and contain active zones within the invagination (Figure 1D).

A modest variety of invaginating presynaptic terminal structures occur, including in developing auditory nerve endbulbs on neuron somas in the cat, vestibular nerve terminals on neuron somas of the rat lateral vestibular nucleus, crested dendrites in the rat interpeduncular nucleus, and cup-shaped spines (see Petralia et al., 2017); also, terminals often partially invaginate (deep indention) into neuron somas in the monkey lateral geniculate nucleus (Saavedra et al., 1968). The crested dendrite is a unique dendritic structure containing several crest spines joined with invaginating presynaptic terminals, found in the interpeduncular nucleus of the rat (Murray et al., 1979). A number of studies have described cup-shaped spines in the cerebral cortex and hippocampus of mammals. Basically, the spine appears to wrap around the smaller presynaptic terminal; the best examples are seen in the rat hippocampal dentate gyrus (Figure 1D; Desmond and Levy, 1983; Frotscher and Léránth, 1986). Presence of cup spines may be affected by neuronal plasticity and they may be more frequent in slice and neuronal cell cultures (Mitchell et al., 2012; Petralia et al., 2017; and unpublished data).

\section{Neuromuscular and Secretomotor Endings}

In neuromuscular junctions (NMJs) of most animals, invertebrate and vertebrate, presynaptic terminals are indenting or invaginating into muscle fibers; thus, some kinds of terminals are found in a shallow, elongate indention ("gutter") on the surface of the fiber, while others are invaginating completely into the fiber (Figure 2B; Petralia et al., 2017). Most skeletal muscles in mammals have twitch fibers, defined by their ability to propagate an action potential along the fiber from the NMJ. In skeletal muscles of mammals (and in vertebrates in general), the NMJ postsynaptic membrane (muscle fiber) is often highly folded into subjunctional folds. This is designed to separate the acetylcholine neurotransmitter receptors on the crests of the folds from the sodium channels at the bottom of the folds, as well as align the receptors with the presynaptic active zones (York and Zheng, 2017). The overall arrangement serves to amplify the response to a relatively small amount of neurotransmitter; this is especially efficient in humans compared to mice and rats, since humans have a relatively smaller NMJ area and larger area of folds compared to mice and rats (and even more so compared to frogs; Martin, 1994; Slater, 2008). In addition, an increased depth of the indention or invagination appears to be tied somewhat to greater depth and complexity of the subjunctional folds, and this also could be related to the response speed of the muscle fibers (e.g., for fast vs. slow twitch fibers; Ellisman et al., 1976; Petralia et al., 2017). Various other kinds of muscle fibers have NMJs that can be indented or invaginated, including the slow (tonic) muscle fibers of ear and extraocular muscles, and muscle spindles, cardiac muscle and smooth muscle in internal organs; they also are found at motor nerve endings in exocrine and endocrine gland cells (reviewed in detail in Petralia et al., 2017).

\section{Category 1+2. Hippocampal Excrescences}

Mossy fiber terminal (MFT) synapses in the CA3 area (and also hilus) of the hippocampus form unusual synapses with invaginating postsynaptic, spine-like processes called thorny excrescences (category 2; Petralia et al., 2015, 2016; also Reberger et al., 2018). They seem to be a specialization largely unique to mammals, although some similar structures are present in lizards (reviewed in Petralia et al., 2016). The large excrescences can contain some structures that are usually absent in typical spines, such as mitochondria, multivesicular bodies (Figures 1C, 2C), ribosomes and a few microtubules. The excrescences are plastic structures and can form new invaginating extensions with new active zones following LTP (Zhao et al., 2012). MFTs originate from granule cells of the dentate gyrus. These specialized synapses may have evolved in mammals to mediate higher abilities for pattern separation of episodic memory (Treves et al., 2008; Schmidt et al., 2012). The distinct advantage of the invagination is evident in the MFT-thorny excrescence structure. Basically, it forms a very large, continuous synaptic membrane compartment with multiple active zones and excludes any glial processes. This special enclosed synaptic environment facilitates presynaptic diffusion of calcium, spillover of neurotransmitter to reach postsynaptic receptors at multiple active zones, and the spread of zinc co-released from the synaptic vesicles with glutamate (Li et al., 2001; Rollenhagen et al., 2007). So, the invaginated environment keeps some components in and excludes others. The circuitry is complicated and will not be described here, but this unusual synapse is "designed to have a higher net probability of release than most other cortical synapses..." (Henze et al., 2000). Hints of a similar design can be found elsewhere. Thus, dendritic excrescences in the rat somatosensory thalamus (ventrobasal complex) are multiple-branched spines somewhat simpler than the hippocampal thorny excrescences (Spacek and Lieberman, 1974); a similar arrangement may occur in the hamster dorsal lateral geniculate nucleus (So et al., 1985). They invaginate deeply into the large presynaptic terminal, that 
is stitched to the dendrite shaft via adherens-like junctions, reminiscent of the hippocampal MFTs.

In adult rats, spinules (category 1) are common on excrescences (Figure 2C; Petralia et al., 2011). Spatial (water maze) training increases the size of the excrescences and the number of spinules, and some spinules may even form bridges between individual thorns of the excrescences (Stewart et al., 2005); environmental enrichment also increases growth and complexity of the excrescences (Gogolla et al., 2009). Spinules may appear to form a contiguous sequence of structures with autophagosomes in the MFT (Petralia et al., 2011), suggesting that the spinules are involved in turnover of the excrescence membrane during activity, as suggested by Tao-Cheng et al. (2009) for hippocampus spinules in general. Interestingly, MFT spinules and autophagosomes label prominently with antibodies to the sonic hedgehog (Shh) signaling receptors, patched and smoothened, perhaps indicating a role for Shh in trans-synaptic signaling at the MFT synapse (Petralia et al., 2011); Shh also promotes autophagy in synaptic terminals (Petralia et al., 2013). Similarly, autophagy of the Wnt-signal mediator, disheveled, is implicated in regulation of Wnt signaling (Gao et al., 2010). In fact, the increased growth/complexity of thorny excrescences in mice exposed to an enriched environment is correlated with an increase in Wnt in the CA3; and it is likely that enhanced behavioral experience increases local signaling of Wnt at these synapses (Gogolla et al., 2009).

\section{Category 2+3. Photoreceptor Terminals}

Photoreceptor terminals of many animals, both invertebrate and vertebrate, typically have invaginating postsynaptic processes (Petralia et al., 2016). In the retina of mammals, as for most vertebrates, the presynaptic terminal active zones of the rod and cone photoreceptor terminals usually have a deep invagination (Figure 2D) typically with 3-4 postsynaptic processes (spines or spine-like processes; category 2) including two from horizontal cell neurons and one or two from bipolar cell neurons (Sterling and Demb, 2004). The neurotransmitter glutamate is released from vesicles associated with ribbonshaped, dense presynaptic structures (i.e., the synaptic ribbon) and diffuses to reach various populations of postsynaptic receptors placed at different distances from the active zone; in cones at least, this includes some receptors below the invagination (Haverkamp et al., 2000, 2001; Sterling and Demb, 2004). The complex structure of the invagination thus can serve to separate different receptor populations at various distances to control responses according to activity, glutamate release volume and subsequent extent of spillover.

Interestingly, at least the horizontal cell processes also appear to act as invaginating presynaptic terminals (category 3); these can be presynaptic to both the photoreceptor terminal and the bipolar cell processes. It is common to find numerous vesicles in the invaginated horizontal cell processes; good examples are found in rats, monkeys and humans; in addition, there is good evidence that the latter processes can be GABAergic (Petralia et al., 2017). However, definitive synapses between presynaptic horizontal cell processes and postsynaptic photoreceptor plus bipolar processes only have been described in the human (Linberg and Fisher, 1988). There is considerable evidence that horizontal processes provide a feedback mechanism to the photoreceptor cell synapse, but the details of the mechanism are debated; generally, this is believed to involve one or more of the following: GABA, protons $(\mathrm{pH})$ and ephaptic transmission (close-range changes in electrical field; Gardner et al., 2015; Kramer and Davenport, 2015; Chapot et al., 2017). Ephaptic transmission might involve connexin hemichannels; these have been found in horizontal cell processes in fish, but it is not clear if they are present in mammalian horizontal cell processes (Klaassen et al., 2011; Gardner et al., 2015; Kramer and Davenport, 2015). Alternatively, both ephaptic and $\mathrm{pH}$-mediated transmission in horizontal cells could be mediated via pannexin-based channels (Kranz et al., 2013; Cenedese et al., 2017; Chapot et al., 2017). In our own studies, we found preliminary evidence of GABA receptor immunogold labeling between horizontal cell processes and adjacent structures, including rod cytoplasmic fingers (Petralia et al., 2017). While GABA transmission, if it occurs, is assumed to involve postsynaptic GABA receptors on the photoreceptor terminal, some evidence indicates that these are autoreceptors on the horizontal cell processes, and they mediate a $\mathrm{pH}$-based feedback (Hirano et al., 2016).

\section{CONCLUSION}

Invaginating structures are common at synapses and are associated either with developmental plasticity or are integral to the mature synapse structure. In some cases, like the hippocampal MFTs or NMJs, mammals may show particularly well-developed invaginating synaptic structures, reflecting perhaps evolutionary enhancements in the mammalian brain and in brain-muscle coordination. The three categories differ in structure, but in all cases, the invaginated synapse forms a special, enclosed environment that allows wide movement of neurotransmitters and/or other chemicals while excluding other substances, leading to modifications in neurotransmission or selective chemical signaling between the neurons. The invagination also may be specialized for signaling via ephaptic conduction. This has been studied so far in only a few areas such as the retina, but it is likely a widespread mechanism for synaptic modulation, as noted by Gardner et al. (2015).

\section{AUTHOR CONTRIBUTIONS}

RSP, MPM and PJY wrote the manuscript and RSP, Y-XW and PJY contributed to the figures.

\section{ACKNOWLEDGMENTS}

This work was supported by the Intramural Research Programs of NIH/NIDCD and NIH/NIA. The code and animal protocol for the Advanced Imaging Core of NIDCD is ZIC DC000081 and $1167-16$, respectively. 


\section{REFERENCES}

Adamo, N. J., and Daigneault, E. A. (1973). Ultrastructural morphology of Schwann cell-neuronal relationships in the spiral ganglia of cats. Am. J. Anat. 138, 73-77. doi: 10.1002/aja.1001380105

Akert, K., Pfenninger, K., and Sandri, C. (1967). The fine structure of synapses of the subfornical organ of the cat. Z. Zellforsch. Mikrosk. Anat. 81, 537-556. doi: $10.1007 /$ bf00541013

Blanque, A., Repetto, D., Rohlmann, A., Brockhaus, J., Duning, K., Pavenstädt, H., et al. (2015). Deletion of KIBRA, protein expressed in kidney and brain, increases filopodial-like long dendritic spines in neocortical and hippocampal neurons in vivo and in vitro. Front. Neuroanat. 9:13. doi: 10.3389/fnana.2015.00013

Boyne, A. F., and Tarrant, S. B. (1982). Pseudopodial interdigitations between abutted nerve terminals: diffusion traps which occur in several nuclei of the rat limbic system. J. Neurosci. 2, 463-469.

Brusco, J., Merlo, S., Ikeda, É. T., Petralia, R. S., Kachar, B., Rasia-Filho, A. A., et al. (2014). Inhibitory and multisynaptic spines and hemispherical synaptic specialization in the posterodorsal medial amygdala of male and female rats. J. Comp. Neurol. 522, 2075-2088. doi: 10.1002/cne.23518

Cenedese, V., de Graaff, W., Csikós, T., Poovayya, M., Zoidl, G., and Kamermans, M. (2017). Pannexin 1 is critically involved in feedback from horizontal cells to cones. Front. Molec. Neurosci. 10:403. doi: 10.3389/fnmol. 2017.00403

Chapot, C. A., Euler, T., and Schubert, T. (2017). How do horizontal cells 'talk' to cone photoreceptors? Different levels of complexity at the cone-horizontal cell synapse. J. Physiol. 595, 5495-5506. doi: 10.1113/JP274177

Desmond, N. L., and Levy, W. B. (1983). Synaptic correlates of associative potentiation/depression: an ultrastructural study in the hippocampus. Brain Res. 265, 21-30. doi: 10.1016/0006-8993(83)91329-x

Eckenhoff, M. F., and Pysh, J. J. (1979). Double-walled coated vesicle formation: evidence for massive and transient conjugate internalization of plasma membranes during cerebellar development. J. Neurocytol. 8, 623-638. doi: 10.1007/bf01208513

Ellisman, M. H., Rash, J. E., Staehelin, L. A., and Porter, K. R. (1976). Studies of excitable membranes. II. A comparison of specializations at neuromuscular junctions and nonjunctional sarcolemmas of mammalian fast and slow twitch muscle fibers. J. Cell Biol. 68, 752-774. doi: 10.1083/jcb.68.3.752

Familtsev, D., Quiggins, R., Masterson, S. P., Dang, W., Slusarczyk, A. S., Petry, H. M., et al. (2016). Ultrastructure of geniculocortical synaptic connections in the tree shrew striate cortex. J. Comp. Neurol. 524, 1292-1306. doi: 10.1002/cne.23907

Fiala, J. C., Feinberg, M., Popov, V., and Harris, K. M. (1998). Synaptogenesis via dendritic filopodia in developing hippocampal area CA1. J. Neurosci. 18, 8900-8911.

Frotscher, M., and Léránth, C. (1986). The cholinergic innervation of the rat fascia dentata: identification of target structures on granule cells by combining choline acetyltransferase immunocytochemistry and Golgi impregnation. J. Comp. Neurol. 243, 58-70. doi: 10.1002/cne.902430106

Gao, C., Cao, W., Bao, L., Zuo, W., Xie, G., Cai, T., et al. (2010). Autophagy negatively regulates $\mathrm{Wnt}$ signalling by promoting Dishevelled degradation. Nat. Cell Biol. 12, 781-790. doi: 10.1038/ncb2082

Gardner, C. L., Jones, J. R., Baer, S. M., and Crook, S. M. (2015). Drift-diffusion simulation of the ephaptic effect in the triad synapse of the retina. J. Comput. Neurosci. 38, 129-142. doi: 10.1007/s10827-014-0531-7

Geinisman, Y., deToledo-Morrell, L., and Morrell, F. (1994). Comparison of structural synaptic modifications induced by long-term potentiation in the hippocampal dentate gyrus of young adult and aged rats. Ann. N Y Acad. Sci. 747, 452-466. doi: 10.1111/j.1749-6632.1994.tb44428.x

Gogolla, N., Galimberti, I., Deguchi, Y., and Caroni, P. (2009). Wnt signaling mediates experience-related regulation of synapse numbers and mossy fiber connectivities in the adult hippocampus. Neuron 62, 510-525. doi: 10.1016/j. neuron.2009.04.022

Haverkamp, S., Grünert, U., and Wässle, H. (2000). The cone pedicle, a complex synapse in the retina. Neuron 27, 85-95. doi: 10.1016/s0896-6273(00)00011-8

Haverkamp, S., Grünert, U., and Wässle, H. (2001). The synaptic architecture of AMPA receptors at the cone pedicle of the primate retina. J. Neurosci. 21, 2488-2500.
Henze, D. A., Urban, N. N., and Barrionuevo, G. (2000). The multifarious hippocampal mossy fiber pathway: a review. Neuroscience 98, 407-427. doi: 10.1016/s0306-4522(00)00146-9

Hirano, A. A., Liu, X., Boulter, J., Grove, J., Pérez de Sevilla Müller, L. Barnes, S., et al. (2016). Targeted deletion of vesicular GABA transporter from retinal horizontal cells eliminates feedback modulation of photoreceptor calcium channels. eNeuro 3:ENEURO.0148-15.2016. doi: 10.1523/ENEURO. 0148-15.2016

Klaassen, L. J., Sun, Z., Steijaert, M. N., Bolte, P., Fahrenfort, I., Sjoerdsma, T., et al. (2011). Synaptic transmission from horizontal cells to cones is impaired by loss of connexin hemichannels. PLoS Biol. 9:e1001107. doi: 10.1371/journal.pbio. 1001107

Kramer, R. H., and Davenport, C. M. (2015). Lateral inhibition in the vertebrate retina: the case of the missing neurotransmitter. PLoS Biol. 13:e1002322. doi: 10.1371/journal.pbio.1002322

Kranz, K., Dorgau, B., Pottek, M., Herrling, R., Schultz, K., Bolte, P., et al. (2013). Expression of Pannexin1 in the outer plexiform layer of the mouse retina and physiological impact of its knockout. J. Comp. Neurol. 521, 1119-1135. doi: $10.1002 /$ cne.23223

Li, Y., Hough, C. J., Frederickson, C. J., and Sarvey, J. M. (2001). Induction of mossy fiber $\rightarrow$ CA3 long-term potentiation requires translocation of synaptically released $\mathrm{Zn}^{2+}$. J. Neurosci. 21, 8015-8025.

Linberg, K. A., and Fisher, S. K. (1988). Ultrastructural evidence that horizontal cell axon terminals are presynaptic in the human retina. J. Comp. Neurol. 268, 281-297. doi: 10.1002/cne.902680211

Martin, A. R. (1994). Amplification of neuromuscular transmission by postjunctional folds. Proc. Biol. Sci. 258, 321-326. doi: 10.1098/rspb. 1994.0180

Mitchell, N., Petralia, R. S., Currier, D. G., Wang, Y. X., Kim, A., Mattson, M. P., et al. (2012). Sonic hedgehog regulates presynaptic terminal size, ultrastructure and function in hippocampal neurons. J. Cell Sci. 125, 4207-4213. doi: $10.1242 /$ jcs. 105080

Murray, M., Zimmer, J., and Raisman, G. (1979). Quantitative electron microscopic evidence for reinnervation in the adult rat interpeduncular nucleus after lesions of the fasciculus retroflexus. J. Comp. Neurol. 187, 447-468. doi: 10.1002/cne.901870211

Novotny, G. E. (1984). Formation of cytoplasm-containing vesicles from doublewalled coated invaginations containing oligodendrocytic cytoplasm at the axon-myelin sheath interface in adult mammalian central nervous system. Acta Anat. Basel. 119, 106-112. doi: 10.1159/000145869

Omiya, Y., Uchigashima, M., Konno, K., Yamasaki, M., Miyazaki, T., Yoshida, T., et al. (2015). VGluT3-expressing CCK-positive basket cells construct invaginating synapses enriched with endocannabinoid signaling proteins in particular cortical and cortex-like amygdaloid regions of mouse brains. J. Neurosci. 35, 4215-4228. doi: 10.1523/JNEUROSCI.4681 $-14.2015$

Ozcan, A. S. (2017). Filopodia: a rapid structural plasticity substrate for fast learning. Front. Synaptic Neurosci. 9:12. doi: 10.3389/fnsyn.2017.00012

Petralia, R. S., Mattson, M. P., and Yao, P. J. (2014). Communication breakdown: the impact of ageing on synapse structure. Ageing Res. Rev. 14, 31-42. doi: 10.1016/j.arr.2014.01.003

Petralia, R. S., Schwartz, C. M., Wang, Y. X., Kawamoto, E. M., Mattson, M. P., and Yao, P. J. (2013). Sonic hedgehog promotes autophagy in hippocampal neurons. Biol. Open 2, 499-504. doi: 10.1242/bio.20134275

Petralia, R. S., Schwartz, C. M., Wang, Y. X., Mattson, M. P., and Yao, P. J. (2011). Subcellular localization of Patched and Smoothened, the receptors for Sonic hedgehog signaling, in the hippocampal neuron. J. Comp. Neurol. 519, 3684-3699. doi: 10.1002/cne.22681

Petralia, R. S., Wang, Y. X., Hua, F., Yi, Z., Zhou, A., Ge, L., et al. (2010). Organization of NMDA receptors at extrasynaptic locations. Neuroscience 167, 68-87. doi: 10.1016/j.neuroscience.2010.01.022

Petralia, R. S., Wang, Y. X., Mattson, M. P., and Yao, P. J. (2015). Structure, distribution, and function of neuronal/synaptic spinules and related invaginating projections. Neuromolecular Med. 17, 211-240. doi: 10.1007/s12017-015-8358-6

Petralia, R. S., Wang, Y. X., Mattson, M. P., and Yao, P. J. (2016). The diversity of spine synapses in animals. Neuromolecular Med. 18, 497-539. doi: $10.1007 / \mathrm{s} 12017-016-8405-y$ 
Petralia, R. S., Wang, Y. X., Mattson, M. P., and Yao, P. J. (2017). Invaginating presynaptic terminals in neuromuscular junctions, photoreceptor terminalsm and other synapses of animals. Neuromolecular Med. 19, 193-240. doi: 10.1007/s12017-017-8445-y

Petralia, R. S., and Wenthold, R. J. (1999). Immunocytochemistry of NMDA receptors. Methods Mol. Biol. 128, 73-92. doi: 10.1385/1-59259-683-5:73

Rao-Mirotznik, R., Harkins, A. B., Buchsbaum, G., and Sterling, P. (1995). Mammalian rod terminal: architecture of a binary synapse. Neuron 14, 561-569. doi: 10.1016/0896-6273(95)90312-7

Reberger, R., Dall'Oglio, A., Jung, C. R., and Rasia-Filho, A. A. (2018). Structure and diversity of human dendritic spines evidenced by a new three-dimensional reconstruction procedure for Golgi staining and light microscopy. J. Neurosci. Methods 293, 27-36. doi: 10.1016/j.jneumeth.2017.09.001

Rodriguez-Moreno, J., Rollenhagen, A., Arlandis, J., Santuy, A., MerchanPérez, A., DeFelipe, J., et al. (2017). Quantitative 3D ultrastructure of thalamocortical synapses from the "lemniscal" ventral posteromedial nucleus in mouse barrel cortex. Cereb. Cortex doi: 10.1093/cercor/bhx187 [Epub ahead of print].

Rollenhagen, A., Sätzler, K., Rodriguez, E. P., Jonas, P., Frotscher, M., and Lübke, J. H. (2007). Structural determinants of transmission at large hippocampal mossy fiber synapses. J. Neurosci. 27, 10434-10444. doi: 10.1523/JNEUROSCI.1946-07.2007

Royer, S. M., and Kinnamon, J. C. (1988). Ultrastructure of mouse foliate taste buds: synaptic and nonsynaptic interactions between taste cells and nerve fibers. J. Comp. Neurol. 270, 11-24, 58-19. doi: 10.1002/cne.902700103

Royer, S. M., and Kinnamon, J. C. (1991). HVEM serial-section analysis of rabbit foliate taste buds: I. Type III cells and their synapses. J. Comp. Neurol. 306, 49-72. doi: 10.1002/cne.903060105

Saavedra, J. P., Vaccarezza, O. L., and Reader, T. A. (1968). Ultrastructure of cells and synapses in the parvocellular portion of the cebus monkey lateral geniculate nucleus. Z. Zellforsch. Mikrosk. Anat. 89, 462-477. doi: 10.1007/bf0 0336173

Schmidt, B., Marrone, D. F., and Markus, E. J. (2012). Disambiguating the similar: the dentate gyrus and pattern separation. Behav. Brain Res. 226, 56-65. doi: 10.1016/j.bbr.2011.08.039

Shepherd, G. M. (2004). The Synaptic Organization of the Brain. 5th Edn. Oxford: Oxford University Press.

Slater, C. R. (2008). Structural factors influencing the efficacy of neuromuscular transmission. Ann. N Y Acad. Sci. 1132, 1-12. doi: 10.1196/annals.1405.003

So, K. F., Campbell, G., and Lieberman, A. R. (1985). Synaptic organization of the dorsal lateral geniculate nucleus in the adult hamster. An electron microscope study using degeneration and horseradish peroxidase tracing techniques. Anat. Embryol. 171, 223-234. doi: 10.1007/bf00341417

Spacek, J., and Harris, K. M. (2004). Trans-endocytosis via spinules in adult rat hippocampus. J. Neurosci. 24, 4233-4241. doi: 10.1523/JNEUROSCI.028704.2004

Spacek, J., and Lieberman, A. R. (1974). Ultrastructure and three-dimensional organization of synaptic glomeruli in rat somatosensory thalamus. J. Anat. 117, 487-516.

Spencer, P. S., and Thomas, P. K. (1974). Ultrastructural studies of the dying-back process. II. The sequestration and removal by Schwann cells and oligodendrocytes of organelles from normal and diseases axons. J. Neurocytol. 3, 763-783. doi: 10.1007/bf01097197
Sterling, P., and Demb, J. B. (2004). "Retina," in The Synaptic Organization of the Brain, 5th Edn. ed. G. M. Shepherd (New York, NY: Oxford University Press), 217-269.

Stewart, M. G., Davies, H. A., Sandi, C., Kraev, I. V., Rogachevsky, V. V., Peddie, C. J., et al. (2005). Stress suppresses and learning induces plasticity in CA3 of rat hippocampus: a three-dimensional ultrastructural study of thorny excrescences and their postsynaptic densities. Neuroscience 131, 43-54. doi: 10.1016/j.neuroscience.2004.10.031

Tao-Cheng, J. H., Dosemeci, A., Gallant, P. E., Miller, S., Galbraith, J. A., Winters, C. A., et al. (2009). Rapid turnover of spinules at synaptic terminals. Neuroscience 160, 42-50. doi: 10.1016/j.neuroscience.2009.02.031

Treves, A., Tashiro, A., Witter, M. P., and Moser, E. I. (2008). What is the mammalian dentate gyrus good for? Neuroscience 154, 1155-1172. doi: 10.1016/j.neuroscience.2008.04.073

Vijayan, V., and Verstreken, P. (2017). Autophagy in the presynaptic compartment in health and disease. J. Cell Biol. 216, 1895-1906. doi: 10.1083/jcb.2016 11113

Westrum, L. E., and Blackstad, T. W. (1962). An electron microscopic study of the stratum radiatum of the rat hippocampus (regio superior, CA 1) with particular emphasis on synaptology. J. Comp. Neurol. 119, 281-309. doi: 10.1002/cne. 901190303

Witt, M., and Reutter, K. (1996). Embryonic and early fetal development of human taste buds: a transmission electron microscopical study. Anat. Rec. 246, 507-523. doi: 10.1002/(sici)1097-0185(199612)246:4<507::aid-ar10>3. $0 . \mathrm{co} ; 2$-s

Yao, P. J., Petralia, R. S., Bushlin, I., Wang, Y., and Furukawa, K. (2005). Synaptic distribution of the endocytic accessory proteins AP180 and CALM. J. Comp. Neurol. 481, 58-69. doi: 10.1002/cne.20362

York, A. L., and Zheng, J. Q. (2017). Super-resolution microscopy reveals a nanoscale organization of acetylcholine receptors for trans-synaptic alignment at neuromuscular synapses. eNeuro 10:ENEURO.0232-17.2017. doi: 10.1523/ENEURO.0232-17.2017

Yoshida, T., Uchigashima, M., Yamasaki, M., Katona, I., Yamazaki, M., Sakimura, K., et al. (2011). Unique inhibitory synapse with particularly rich endocannabinoid signaling machinery on pyramidal neurons in basal amygdaloid nucleus. Proc. Natl. Acad. Sci. U S A 108, 3059-3064. doi: $10.1073 /$ pnas. 1012875108

Zhao, S., Studer, D., Chai, X., Graber, W., Brose, N., Nestel, S., et al. (2012). Structural plasticity of hippocampal mossy fiber synapses as revealed by high-pressure freezing. J. Comp. Neurol. 520, 2340-2351. doi: 10.1002/cne. 23040

Conflict of Interest Statement: The authors declare that the research was conducted in the absence of any commercial or financial relationships that could be construed as a potential conflict of interest.

Copyright (c) 2018 Petralia, Wang, Mattson and Yao. This is an open-access article distributed under the terms of the Creative Commons Attribution License (CC BY). The use, distribution or reproduction in other forums is permitted, provided the original author(s) and the copyright owner are credited and that the original publication in this journal is cited, in accordance with accepted academic practice. No use, distribution or reproduction is permitted which does not comply with these terms. 